\title{
Identification, phylogenetic analysis and expression profile of an anionic insect defensin gene, with antibacterial activity, from bacterial- challenged cotton leafworm, Spodoptera littoralis
}

\author{
AlaaEddeen M Seufi ${ }^{{ }^{*}}$, Elsayed E Hafez ${ }^{2}$ and Fatma H Galal'
}

\begin{abstract}
Background: Defensins are a well known family of cationic antibacterial peptides (AMPs) isolated from fungi, plants, insects, mussels, birds, and various mammals. They are predominantly active against gram (+) bacteria, and a few of them are also active against gram (-) bacteria and fungi. All insect defensins belonging to the invertebrate class have a consensus motif, $C-X_{5-16}-C-X_{3}-C-X_{9-10}-C-X_{4-7}-C X_{1}-C$. Only seven AMPs have already been found in different lepidopteran species. No report was published on the isolation of defensin from the Egyptian cotton leafworm, Spodoptera littoralis.

Results: An anionic defensin, termed SpliDef, was isolated from the haemolymph of the cotton leafworm, $S$. littoralis, after bacterial challenge using differential display technique. Based on sequence analyses of the data, specific primers for full length and mature peptide of defensin were designed and successfully amplified 471 and $150 \mathrm{bp}$ amplicons. The integration of the results revealed that the $471 \mathrm{bp}-\mathrm{PCR}$ product has one open reading frame (orf) of $303 \mathrm{bp}$ long, including both start codon (AUG) and stop codon (UGA). The deduced peptide consists of a 23-residues signal peptide, a 27-residues propeptide and a 50-residues mature peptide with the conserved sixcysteine motif of insect defensins. Both haemolymph and expressed protein exhibited antibacterial activities comparable to positive control. The RT-qPCR indicated that it was more than 41 -folds up-regulated at $48 \mathrm{~h}$ p.i.

Conclusion: Our results highlight an important immune role of the defensin gene in Spodoptera littoralis by cooperating with other AMPs to control bacterial infection.
\end{abstract}

\section{Background}

The growing problem of resistance of microorganisms to current antibiotics has fostered the search for novel antimicrobial therapies [1]. Particularly interesting are antimicrobial peptides (AMPs) discovered as components of unspecific innate mechanisms of infection fighting in humans and animals [2]. AMPs play a crucial role in innate immune systems of invertebrates, which do not have an adaptive immunity. Insects protect themselves from pathogens and parasites via a powerful innate immune system. Insect innate immune responses include cellular and humoral responses, and humoral responses

\footnotetext{
* Correspondence: alaaseufi@yahoo.com

'Department of Entomology, Faculty of Science, Cairo university, 9 Gamaa St. Giza, 12613, Egypt

Full list of author information is available at the end of the article
}

contain melanization and synthesis of antimicrobial peptides (AMPs). The insect immune responses are based on: the recognition of the pathogen as nonself, the induction of suitable genes and biochemical pathways that result in the production of a potent arsenal of low molecular weight AMPs $[3,4]$. Most of these peptides (AMPs) are produced in the fat body or haemocytes of the insect and released into the haemolymph. Insect AMPs are divided into three groups in accordance to their amino acid sequence and structural features: (i) cecropins which are linear peptides that form $\alpha$-helix and lack cysteine residues; (ii) defensins which have a characteristic six to eight conserved cysteine residues that form a stabilizing array of three or four intramolecular disulfide bridges and three domains consisting in a flexible amino-terminal loop, a central $\alpha$-helix and a carboxyl-terminal 
antiparallel $\beta$-sheet [5-7]; and (iii) peptides with an overrepresentation of proline and/or glycine residues, e.g., lebocins and moricins [7].

Defensins have been isolated from fungi, plants, insects, mussels, birds, and various mammals. They are predominantly active against gram $(+)$ bacteria, and a few of them are also active against gram (-) bacteria and fungi. Regarding the spacing pattern of cysteines, defensins are divided into plant, invertebrate, $\alpha, \beta$-, and -subfamilies [8]. All insect defensins belonging to the invertebrate class have a consensus motif, $\mathrm{C}-\mathrm{X}_{5-16}-\mathrm{C}-\mathrm{X}_{3}-\mathrm{C}-\mathrm{X}_{9-10^{-}} \mathrm{C}$ $\mathrm{X}_{4-7}-\mathrm{CX}_{1}-\mathrm{C}$. To date, hundreds of AMPs have been described in insects and a lot of different nucleotide and amino acid defensin or defensin-like sequences from many insect species were registered by NCBI data base. However, only seven authors reported the presence of defensin-like peptides in Lepidoptera [8-14]. Several AMPs have already been found in different species of Spodoptera. These include moricins, cecropins and defensin, but no report was published on the isolation of defensin from the Egyptian cotton leafworm, Spodoptera littoralis. Therefore, the main objective of the present research was to investigate the immune responses of the Egyptian S. littoralis, to bacterial challenge. Here we report the isolation, sequence characterization, phylogenetic analysis, antimicrobial activity and expression profile of a defensin gene from the haemolymph of S. littoralis.

\section{Results}

Differential display (DD-PCR) using primers corresponding to well known defense genes

As the identification of the induced antibacterial genes was the main objective of this study, differential display technique was used to characterize the genetic variation (at RNA level) between bacterial-challenged and control S. littoralis. Figure 1 shows the results of differentially displayed cDNAs of bacterial-challenged and control insects using 10 primers (Table 1) corresponding to well known defense genes. Haemolymph samples were differentially displayed at 24, 48 and/or 72 h post-infection (p.i.) with S. aureus, $S$. sanguinis and E. coli bacterial strains. It was observed that $S$. aureus-challenged insects died 24 h p.i., E. colichallenged insects died $48 \mathrm{~h}$ p.i. and S. sanguinischallenged insects died $72 \mathrm{~h}$ p.i. Differential display results revealed that the average number of bands per sample was 4.1 bands. The total number of bands resolved in 1.5\% agarose gel for both control and challenged insects was 332 (molecular size ranged from $>1000$ to $\sim 80 \mathrm{bp}$ ). 146 polymorphic bands $(44 \%)$ were differentially displayed with 7 of the used primers. Eight reproducible, treatmentinduced bands were cloned and sequenced using $\mathrm{M}_{13}$ universal primer.

\section{Primer design, RT-PCR amplification and cloning of defensin gene}

Specific primers for the full length and mature peptide of defensin gene were designed. These primers would be used later in the following reactions during this study. Nucleotide sequence of the used primers was illustrated in Table 1. PCR was optimized for each primer set and primers successfully produced positive PCR amplicons of 471 and $150 \mathrm{bp}$ for the full length and mature peptide sequences, respectively (Figure $2 \mathrm{~A}$ ). The full length fragment includes one open reading frame (orf) of defensin gene (positions 125 (AUG) - 427 (UGA)). Subsequently this segment (SpliDef) was cloned into PCR-TOPO vector (Figure 2B, lane 2) and transformed cells were tested with PCR using the same primers (Figure 2B, lane 4). Using this screening method, clone PCR-TOPOSpliDef was tested as positive (Figure 2B, lane 4). A PCR product corresponding to the mature defensin peptide was also cloned into $p$ PROEXTM HTa expression vector and transformed $\mathrm{DH}_{5 \alpha}$ cells were tested as positive (Figure 2A, lane 3).

\section{Nucleotide sequence and sequence analyses}

Nucleotide sequences of SpliDef and its deduced amino acid sequence are shown in Figure 3. A single orf that could encode a polypeptide of 100 amino acids was detected for SpliDef. One stop codon was found at the 3 ' end of the sequence. The flanking region of the initiation codon ATG is ATAATGAG, and the length of 3 untranslated region was 45 bp before the poly (A) track (Figure 3). TATA box as well as GATA, IL-6-RE, and CATT recognition sites were detected in the sequence of promoter region of defensin 321 bp upstream from the start codon. The putative polyadenylation sequence AATAAAA was located 25 bp downstream from the stop codon (Figure 3). The identified defensin orf includes signal peptide (69 bp), propeptide ( $81 \mathrm{bp}$ ) and mature peptide (150 bp). The deduced SpliDef polypeptide (prepropeptide) contains 14 strongly basic, 7 strongly acidic, 48 hydrophobic and 31 polar amino acids. The calculated molecular masses of the full length and mature defensins, were 11.6 and $5.7 \mathrm{KDa}$, respectively, and the calculated isoelectric points (PIs) were 8.5 and 4.3 , respectively. The net charges at $\mathrm{pH} 7.0$ were 4.8 and -5.1, respectively. The defensin prepropeptide was less stable (Instability Index (II): 33.32) than its mature peptide (II: 21.09). Ratios of hydrophilic residues were 31 and 30\% for prepropeptide and mature defensin peptide, respectively.

On comparing SpliDef nucleotide sequence (Acc\# HQ603825) to S. frugiperda defensin and spodoptericin, T. $n i$ defensin and St. albicosta sequence (Acc\# AY128091, AY238439, EU016385 and EZ596498, respectively), 14, 14, 


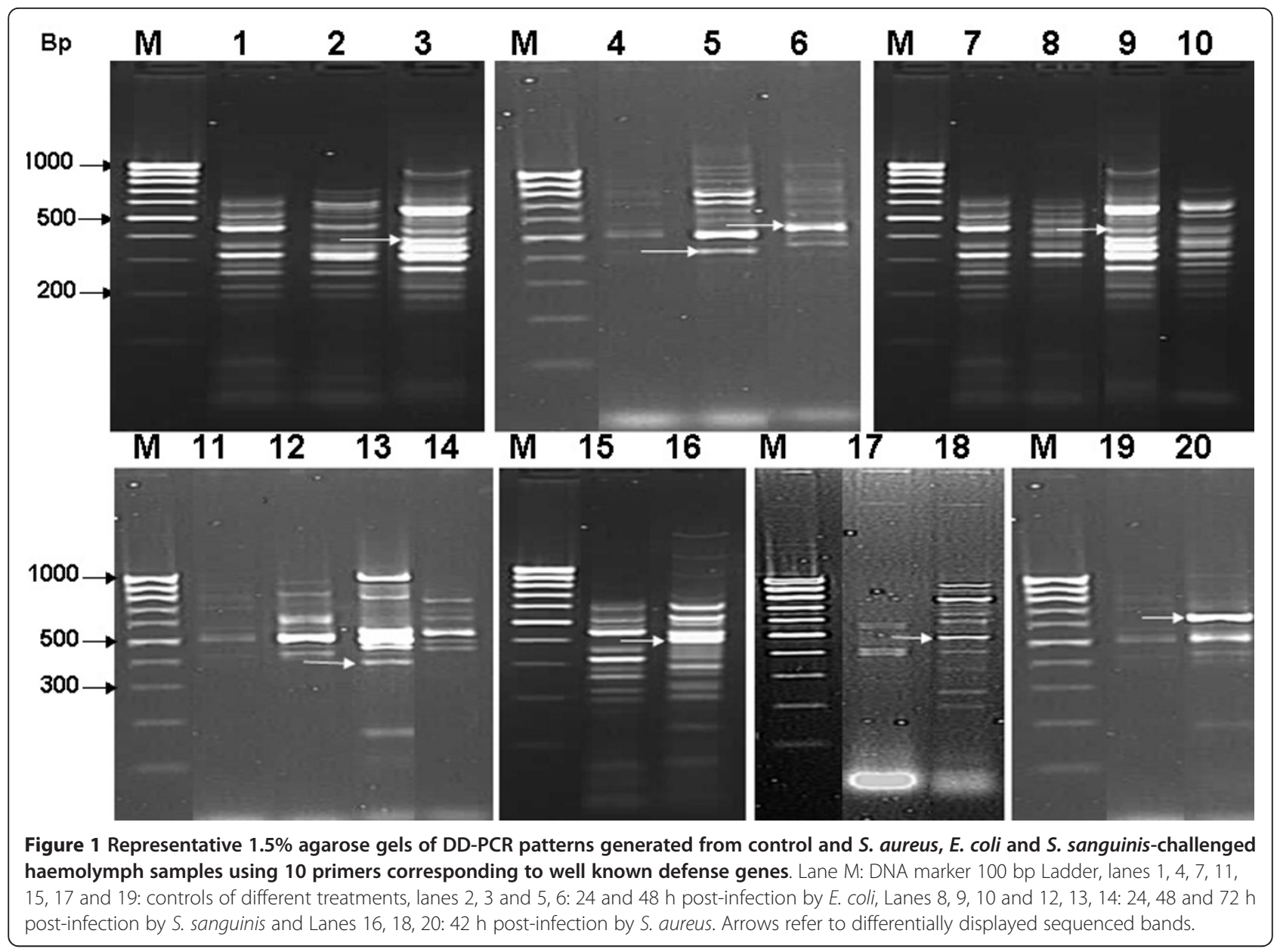

36 and 112 different nucleotides; zero, zero, one and 9 gaps; and 29, 40, zero and zero additions were observed throughout the compared DNA segments (Figure 4).

In addition, the deduced amino acid sequence of SpliDef was blasted to all defensin-related sequences in GenBank database. Blast search created significant alignment with 13 insect-published peptide sequences (9 defensins, 2 spodoptericins and other 2 mRNA products). The SpliDef putative peptide exhibited $96 \%$ identity with S. frugiperda defensin and 2 spodoptericins (Acc\# AAM96925, AAQ18894 and AAQ18895, respectively), 67\% identity with 3 Bombyx mori defensin-like proteins (Acc\# NP_001037370, AAZ38358 and BAG48202), 75, 66, 40, 40 and $48 \%$ identity with the defensins of T. ni, Manduca sexta, Lutzomyia longipalpis and Anopheles sp. (Acc\# ABV688523, ACX49766, ABR28349, ABV60344, respectively), and $31 \%$ identity with both Drosophila yakuba mRNA products (Acc\# XP_002100630 and EDX01738).

On comparing amino acid sequence of the putative polypeptide of SpliDef (HQ603825) to its corresponding sequences of B. mori, S. frugiperda, S. frugiperda spodoptericin, S. frugiperda spodoptericin, T. ni, G. mellonella, Mamestra brassicae, M. sexta, D. melanogaster, Copris tripartitus, Apis cerana cerana and Rhodnius prolixus (Acc\# AAZ38358, AAM96925, AAQ18895, AAQ 18894, ABV68852, AAS19170, AAL69980, ACX49766, CAA81760, ABP97087, ACH96412 and AAO74624, respectively), 6 conserved cysteine residues were observed throughout the 13 compared putative polypeptides (Figure 5). It is noteworthy to mention that SpliDef amino acid sequence contains 8 cysteine residues ( 2 residues in the signal peptide sequence and other 6 residues in the mature peptide). These are comparable to $M$. brassicae and $C$. tripartitus conserved cysteine motifs (Figure 5). B. mori and A. cerana defensins were observed to have only 6 conserved cysteine motifs. Meanwhile, all other compared defensins contains more than 6 (7 or 8 ) conserved cysteine motifs (Figure 5). The spacing pattern of SpliDef six-cysteine residues motif was C- $\mathrm{X}_{10}-\mathrm{C}-\mathrm{X}_{3}-\mathrm{C}$ $\mathrm{X}_{9}-\mathrm{C}-\mathrm{X}_{4}-\mathrm{C}-\mathrm{X}_{1}-\mathrm{C}$, which was consistent with the consensus motif of invertebrate defensins. In addition to the precise conservation of the six cysteines, at least six residues within the cysteine motif of SpliDef, His ${ }^{77}, \mathrm{Leu}^{79}, \mathrm{Lys}^{81}$, Gly $^{82}, \mathrm{Tyr}^{83}$ and Gly ${ }^{86}$ were found to be conserved at 
Table 1 Key table for the primers used in DD-PCR study providing their names, origin and sequences

\begin{tabular}{ccc}
\hline Primer name & Origin & Sequence $\left(\mathbf{5}^{\prime} \mathbf{-} \mathbf{3}^{\prime}\right)$ \\
\hline CHIF & Chitinase-based & TGCCTTGATTCAGTCATC \\
\hline CHIR & Chitinase-based & AATAATCGACTCCAATACG \\
\hline EGF & Endoglucanase-based & TCCGGGTATGTTATGGAAGA \\
\hline EGR & Endoglucanase-based & GGCCATCCACTCTCAGACACA \\
\hline LECF & Lectin-based & ATGGGATCCAAGCAACAGAG \\
\hline LECR & Lectin-based & ATCCTTCAAAGACACAATGTCG \\
\hline IDF & CCAAATGCCTCGTCATCT \\
\hline IDR & Insect defensin-based & ATTAGAGTCAAGCTAAAAGGG \\
\hline HDF & Insect defensin-based & TATTTCTTCTTCGGCAGC \\
\hline HDR & Human defensin-based & GTTCGTCTATTTTGTGCCG \\
\hline FLDefF & Human defensin-based & ACTTAAAAATCTATCATTGGCGTCA \\
\hline FLDefR & Full length defensin & GTTCATGCGATTCGAGGAAGCC \\
\hline MPDefF & Full length defensin & TCATGTGTAGGTATTGTGTACC \\
\hline MPDefR & Mature peptide defensin & GGTCCCTGACTGATCCCTGG
\end{tabular}

All oligonucleotides were synthesized by Invitrogen, USA and HPLC purified.

equivalent positions in the sequences of some other insect defensins (Figure 5).

Primary, secondary structure analyses, post-translational modifications and topology predictions revealed that amino acid sequence of the putative SpliDef peptide has 3 signal peptide cleavage sites (between positions 23-24/3233/34-35), three O-GlcNAcylated residues (1 Ser and 2 Thr at positions 80,37 and 100, respectively) and one potential glycated lysine at position 39 . Two phosphorylation sites (Ser: 1 at position 52, Thr: 1 at position 40) and 13 (7 S, 2 Y and 4 T) kinase specific phosphorylation sites (highest score: $0.89 \mathrm{PKC}$ at position 40 ) were predicted.

\section{Phylogenetic analyses of the SpliDef sequence}

Phylogenetic analyses have been performed on the SpliDef nucleotide seuquence and its deduced polypeptide and the

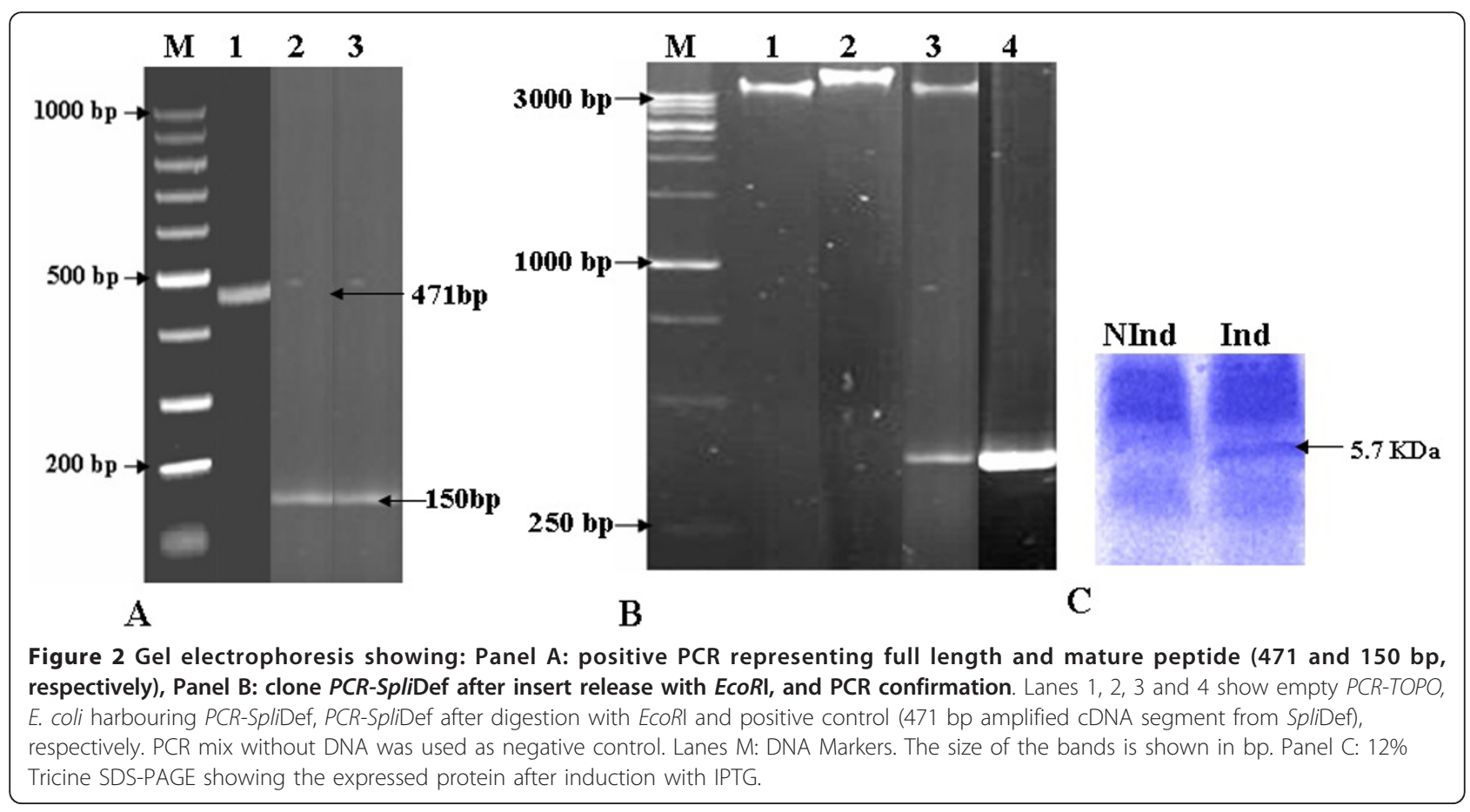




\begin{abstract}
PROMOTOR SEQUENCE
GGCCCCGGTCTAGTTTTTTGTTTTATTTAAAGGGCCCGGGAAATTGCGCGCAAGAGAGTTT TTTTGTTCGTCTATTTTAACCCAAACGTTCCGAAGATAANTGGGAGTTTACGGAAGATCTATA CCGGTTACGTCGGCTATTCGTCGTCTATTTTAACCCAATTTTACGGAAGATAAATACCGGTTA CGTCGGCGTATATTTTTGTGCCGTATAACGTCGGCTATTCGTTAGATAGCTGTTTACCATTAA CCACGTTCATTTCCTTGTATCATTAATCTGGGACGGAAGATCAANTGGGTGTTAAGGTTATA TAAATA
\end{abstract}

PREPROPE PTIDE SEQUENCE

\begin{tabular}{|c|c|c|c|c|c|c|c|c|c|c|c|}
\hline $\mathrm{ATG}$ & AGT & TTC & AGC & TGT & TTG & CGG & TGT & CGG & CTT & GTC & TGG \\
\hline M & $\mathbf{S}$ & $\mathbf{F}$ & $\mathbf{S}$ & $\mathrm{C}$ & L & $\mathbf{R}$ & C & $\mathbf{R}$ & L & V & 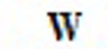 \\
\hline $\mathrm{TAC}$ & $\mathrm{ACG}$ & $\mathrm{CCG}$ & TTG & CTG & GGA & $\mathrm{AGC}$ & CGA & ATC & CAA & GGG & $\mathrm{ACA}$ \\
\hline $\mathbf{Y}$ & $\mathbf{T}$ & $\mathbf{P}$ & L & $\mathrm{L}$ & G & $\mathbf{S}$ & R & I & & G & 1 \\
\hline GTT & CTG & TTG & TGG & $\mathrm{AGG}$ & $A G C$ & $\mathrm{AGA}$ & GCC & TGG & $\mathrm{GCC}$ & $\mathrm{CCA}$ & $\mathrm{TCC}$ \\
\hline V & $\mathrm{L}$ & L & W & $\mathbf{R}$ & $\mathbf{S}$ & $\mathbf{R}$ & A & W & A & $\mathbf{P}$ & \\
\hline $\mathrm{ACA}$ & ATG & $\mathrm{AAG}$ & $\mathrm{ACT}$ & TGG & $\mathrm{AAG}$ & TTA & $\mathrm{AAG}$ & $\mathrm{CCA}$ & AGG & ATC & $\mathrm{CCG}$ \\
\hline $\mathbf{T}$ & M & $\mathbf{K}$ & $T$ & W & $\mathrm{K}$ & L & $\mathrm{K}$ & $\mathbf{P}$ & $\mathbf{R}$ & I & \\
\hline GGG & $\mathrm{CGA}$ & GTT & TCA & TGC & GAT & TTC & GAG & GAA & $\mathrm{GCC}$ & $\mathrm{AAC}$ & GAG \\
\hline & & & & & & $\mathrm{F}$ & $\mathrm{E}$ & E & & & \\
\hline $\mathrm{GAC}$ & GCG & GTG & TGT & $\mathrm{CAG}$ & GAG & CAT & TGT & CTA & $\mathrm{CCA}$ & $\mathrm{AAA}$ & GG \\
\hline & & $\mathrm{V}$ & C & 0 & $\mathrm{E}$ & $\mathrm{H}$ & $\mathrm{C}$ & & & $n$ & \\
\hline C & $\mathrm{ACA}$ & TAC & GGC & ATC & TGC & GTC & AGT & $\overline{\mathrm{CAC}}$ & $\mathrm{ACA}$ & TGT & AGC \\
\hline & & $\mathbf{Y}$ & G & I & C & V & $\mathbf{S}$ & $\mathrm{H}$ & T & C & 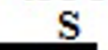 \\
\hline TGC & $\mathrm{ArT}$ & TAT & ATA & GIA & GAA & TIA & ATI & AAA & IGG & TAC & $\mathrm{ACA}$ \\
\hline & & Y & & V & E & & & $\mathrm{K}$ & $\mathrm{IV}$ & V & \\
\hline AAT & $\mathrm{ACC}$ & TAC & $\mathrm{ACA}$ & TGA & $3 \mathrm{UTH}$ & & & & & & \\
\hline
\end{tabular}

Figure 3 Nucleotide and corresponding deduced amino acid sequence of S. littoralis defensin gene (SpliDef). In promoter sequence, TATA, CATT, IL-6-RE and GATA transcription factors are underlined. Cleavage sites of signal and propeptides are indicated by arrows. Mature peptide is double underlined. Asterisk indicates the stop codon. Boxed sequence represents the putative polyadenylation signal.

results of these analyses are shown in Figure 6. In the case of SpliDef nucleotide seuquence, a phylogenetic tree was generated from 38 defensin-related sequences (19 insect species including 7 Lepidoptera, 6 Diptera, 3 Coleoptera, 1 Hymenoptera, 1 Hemiptera and 1 Thysanura) by neighbor-joining distance analysis with maximum sequence difference 1.0 (Figure 6). The topology shows two distinct lineages including 20 (Lepidoptera, Diptera and Hemiptera) and 18 (Lepidoptera, Diptera, Coleoptera, Hymeonoptera and Thysanura) defensin-related sequences, respectively. The maximum nucleotide sequence divergence was exhibited in the first lineage (10 phylogenetic groups). Meanwhile, the defensin sequences appear in the other lineage as less divergent clades (8 phylogenetic groups). The SpliDef was clustered with other 4 lepidopteran sequences, S. frugiperda defensin (Acc\# AAM 96925), spodoptericins (Acc\# AAQ18895 and Acc\#
AAQ18894) and S. albicosta (Acc\# EZ585033), in a monophyletic sister clade (Figure 6). Meanwhile, the other 5 lepidopteran sequences were diverged in different phylogenetic clades (Figure 6). In the case of SpliDef deduced amino acid seuquence, a phylogenetic tree was generated from sequence data of 28 published sequences (18 insect species including 6 Lepidoptera, 6 Diptera, 4 Coleoptera, 1 Hymenoptera and 1 Hemiptera) by neighbor-joining distance analysis with maximum sequence difference 1.0 (Figure 6). The topology shows two distinct lineages including 8 (Lepidoptera and Diptera) and 20 (Lepidoptera, Diptera, Coleoptera, Hymenoptera and Hemiptera) defensin peptides, respectively. The maximum divergence of amino acid sequences was exhibited in lineage II (11 phylogenetic groups). However, less divergence was observed in the other lineage (5 phylogenetic groups). The SpliDef putative peptide was clustered with other 4 


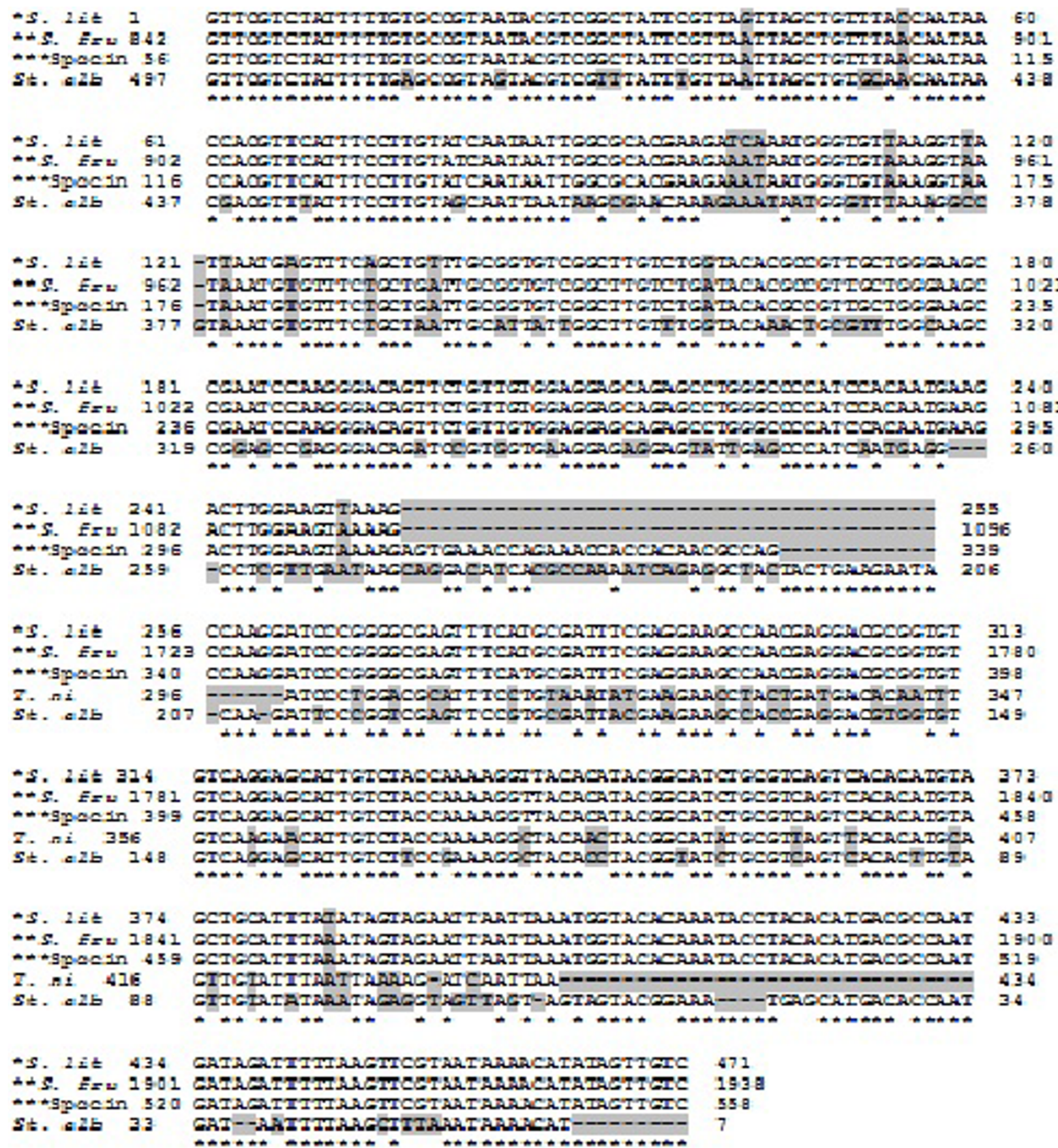

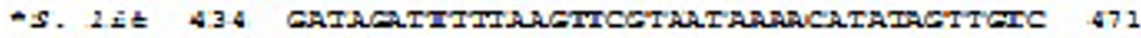

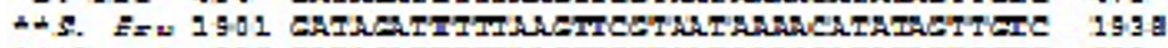

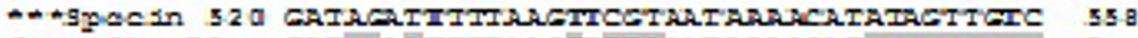

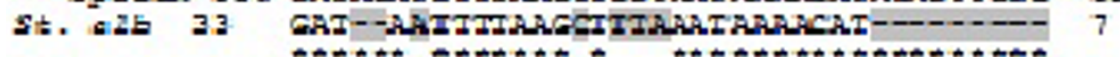

Figure 4 Comparison of defensin nucleotide sequence from S. littoralis (Acc\# HQ603825) with S. frugiperda defensin, spodoptericin, $T$. ni defensin and St. albicosta sequence (Acc\# AY128091, AY238439, EU016385 and EZ596498, respectively). ${ }^{*}$ S. lit: S. littoralis defensin, ${ }^{* *}$ S. fru: S. frugiperda defensin and ${ }^{* *}$ Spocin: S. frugiperda spodoptericin. Gaps and different nucleotides are shaded.

lepidopteran (S. frugiperda, T. ni, Galleria mellonella and Bombyx mori) and one dipteran (D. melanogaster) defensins in a monophyletic sister clade (Figure 6). Meanwhile, the $5^{\text {th }}$ lepidopteran sequence was grouped in a different phylogenetic group (Figure 6).
Quantitative protein analysis

Quantitative protein analysis of the crude haemolymph of control and bacterial-challenged S. littoralis was determined at 1, 6, 12, 24, 48 and $72 \mathrm{~h}$ p.i. (Table 2). Statistical analysis of data revealed that the increase of 


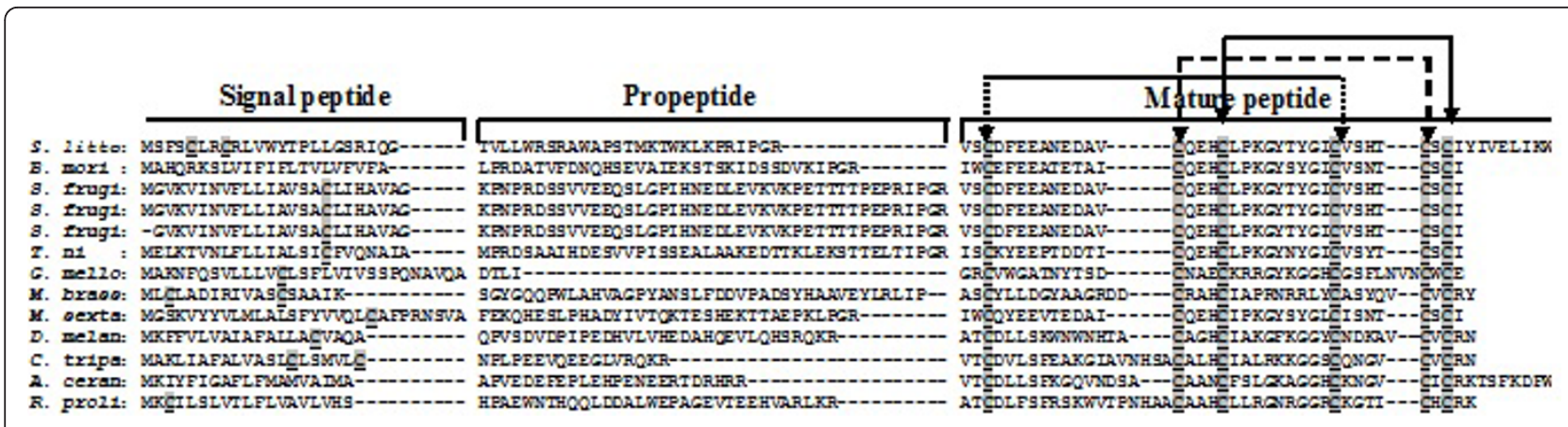

Figure 5 Alignment of SpliDef (HQ603825) deduced amino acid sequence with other insect defensins. The conserved cysteine residues are shaded. AAZ38358: B. mori, AAM96925: S. frugiperda, AAQ18895: S. frugiperda spodoptericin, AAQ18894: S. frugiperda spodoptericin, ABV68852: T. ni, AAS19170: G. mellonella, AAL69980: Mamestra brassicae, ACX49766: Manduca sexta, CAA81760: Drosophila melanogaster, ABP97087: Copris tripartitus, ACH96412: Apis cerana cerana, AAO74624: Rhodnius prolixus.

total protein content in the case of bacterial-challenged insects was significant at all the tested times. $D f, F$ and $P$ values were illustrated in Table 2 . The expected antibacterial peptide concentration in the haemolymph of bacterial-challenged insects was increasing smoothly with the time and an abrupt peak was observed at $48 \mathrm{~h}$ p.i. In addition, the total protein concentration of IPTGinduced, non-induced transformed E. coli and Ni-affinity purified defensin mature peptide was determined at 1,2 and $3 \mathrm{~h}$ p.i. (Table 2). The protein concentration increased with the time course reaching maximum at $3 \mathrm{~h}$ p.i. Statistical analysis of data revealed that the difference of protein content (expressed protein) in the case of IPTG-induced and non-induced cells was significant at all the tested times. $F$ and $P$ values were illustrated in Table 2 . The quantity of protein lost by purification (loss due to purification $=$ induced - noninduced - purified) was 65.8, 167.6 and $60.4 \mu \mathrm{g}$ at 1,2 and $3 \mathrm{~h}$ p.i., respectively. This loss was statistically significant $(P=0.00)$ in all the tested cases.

\section{Antibacterial assay}

Table 3 shows a summary of the antimicrobial screening of the immunized haemolymph and the $\mathrm{Ni}$-affinity purified mature SpliDef peptide (Figure 2C) based on microbial growth inhibition zone (in $\mathrm{mm}$ ). Significant activity was found against gram (-) and gram (+) bacteria for both the immunized haemolymph and the purified defensin (Table 3). Notably the antibacterial activities of both immunized haemolymph and purified defensin $48 \mathrm{~h}$ p.i. were more than $24 \mathrm{~h}$ p.i. for all tested gram (-) bacteria. As for the activity 24 and $48 \mathrm{~h}$ p.i. against gram (+) bacteria, no difference was observed in the case of $S$. sanguinis and a slight difference was observed in the case of purified defensin with $S$. aureus bacteria. The antibacterial activity of the immunized haemolymph was comparable to the positive control in the case of $P$. vulgaris and exceeded it against the other tested gram (+) and gram (-) bacteria,
$48 \mathrm{~h}$ p.i. Meanwhile, the antibacterial activity of the purified defensin was comparable to in the case of $P$. vulgaris and $K$. pneumoniae and more than the positive control against $E$. coli, S. aureus and S. sanguinis bacteria, 48 h p.i.

\section{RT-qPCR}

SpliDef transcript profiles from larval haemolymph of the control and the bacterial-challenged $S$. littoralis were compared at 1, 6, 12, 24, 48 and 72 h p.i. using RT-qPCR (Figure 7). The SpliDef gene was up-regulated by bacterial-challenge at 1, 6, 12, 24, 48 and $72 \mathrm{~h}$ p.i. (2-folds, 3.25-folds, 5.7-folds, 7.9-folds, 41.4-folds and 12.9-folds, respectively). Statistically significant changes were observed between the control and the treated samples at 48 and 72 h p.i. $(d f=4, F=101.44, P=0.00)$. Notably, it was more than 41 -folds up-regulated at $48 \mathrm{~h}$ p.i. No statistically significant change was observed between the control and the treated samples at $1,6,12$ or 24 h p.i. ( $d f$ $=4, F=101.44, P>0.05)$.

\section{Discussion}

In the present study, DD-PCR revealed that several common bands were observed in both control and challenged samples (house keeping genes). Very few bands were recorded in control insects and disappeared in challenged ones (genes were turned off). On the other hand, many bands were induced as a result of bacterial-challenge at different time intervals post-infection. DD-PCR technique is considered a powerful genetic screening tool for complicated dynamic tissue processes, particularly when multiple, limited-sized samples are involved, because it allows for simultaneous amplification of multiple arbitrary transcripts [15]. This technique has been developed as a tool to detect and compare altered gene expression in eukaryotic cells [16], to screen mRNAs, and to characterize differentially expressed mRNAs [17-20]. Many publications described the enhancement of the insect immune system and induction of AMPs due to stress and/or bacterial 


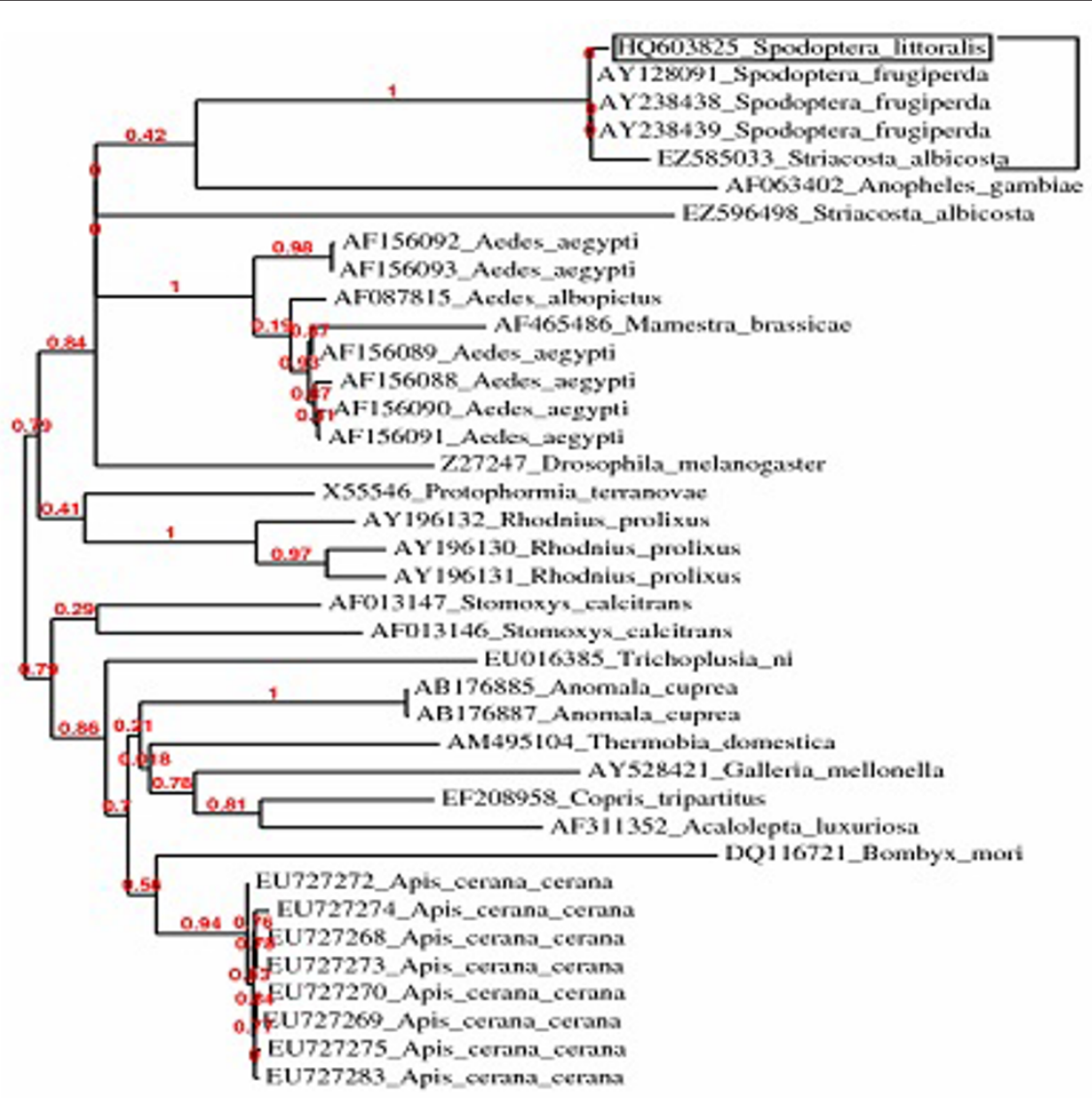

0.6

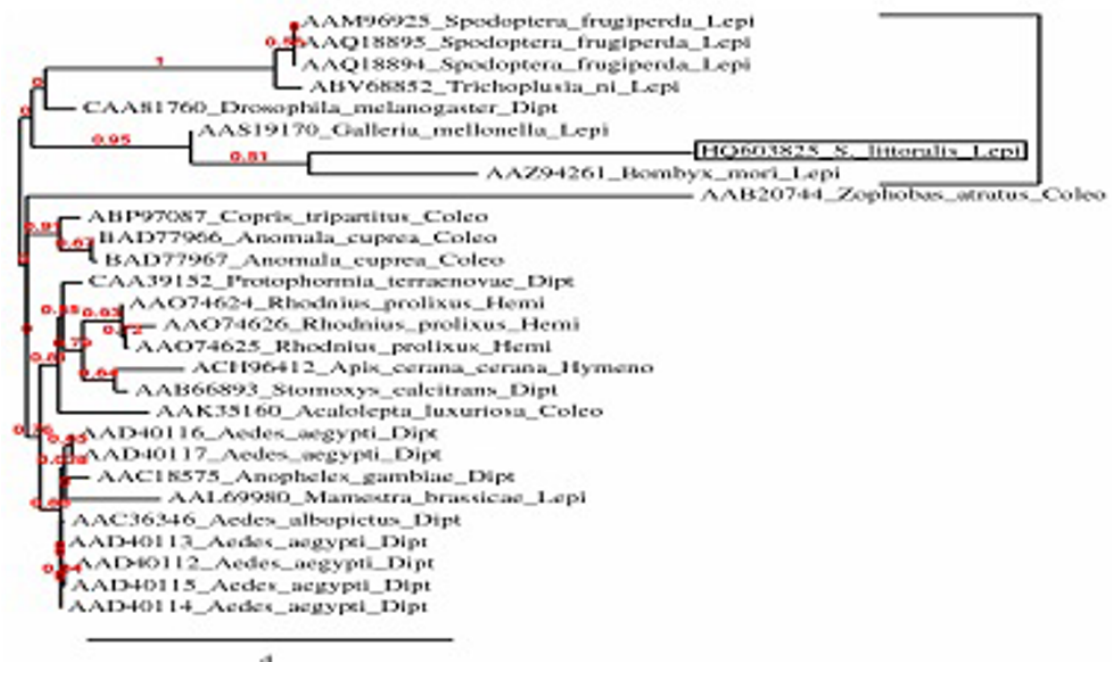

Figure 6 Phylogenetic analysis of SpliDef nucleotide and its deduced amino acid sequences compared to 37 and 27 sequences registered in NCBI. Phylogenetic trees were generated from 38 and 28 defensin-related sequences by neighbor-joining distance analysis using Phylogeny.fr web service, One Click mode. Full sequence names and accession numbers are included in the tree.

challenge [8-10,12,13,21-24]. Although defensin genes were isolated from six insect orders; Lepidoptera, Diptera, Coleoptera, Hymenoptera, Hemiptera and Thysanura, the lepidopteran defensin-like genes included both the smallest (G. mellonella (216 bp), Acc\# AAS19170) and the largest (S. frugiperda (306 bp), Acc\# AAM96925) molecular- 
Table 2 Quantitative protein analysis of the immunized haemolymph of S. littoralis and the purified defensin peptide after induction of the recombinant $E$. coli by IPTG

\begin{tabular}{|c|c|c|c|c|c|c|c|c|}
\hline \multicolumn{9}{|c|}{$\begin{array}{l}\text { Protein concentration at different hours post-infection }(\mu \mathrm{g} / \mathrm{ml}) \\
\qquad \text { Mean } \pm \text { S.E. }\end{array}$} \\
\hline & $1 \mathrm{~h}$ & $2 \mathrm{~h}$ & $3 \mathrm{~h}$ & $6 \mathrm{~h}$ & $12 \mathrm{~h}$ & $24 \mathrm{~h}$ & $48 \mathrm{~h}$ & $72 \mathrm{~h}$ \\
\hline Cont-H & $588 \pm 6.1$ & - & - & $624.8 \pm 6.4$ & $620.2 \pm 4.8$ & $651.4 \pm 7.5$ & $645.4 \pm 5.3$ & $675.6 \pm 2.5$ \\
\hline Inf-H & $687.8 \pm 8.9$ & - & - & $908.2 \pm 7.2$ & $919.4 \pm 4.7$ & $948.8 \pm 6.2$ & $2017.6 \pm 9.5$ & $1316.4 \pm 13.0$ \\
\hline Expec. A.B. & 99.8 & - & - & 283.4 & 299.2 & 297.4 & 1372.1 & 640.8 \\
\hline Induced & $909 \pm 4.9$ & $1057.2 \pm 30.5$ & $1413.2 \pm 38.9$ & - & - & - & - & - \\
\hline Nonlnd & $702.2 \pm 6.0$ & $725.8 \pm 6.4$ & $938.8 \pm 14.1$ & - & - & - & - & \\
\hline Expressed $\mathrm{P}$. & $206.8 \pm 3.8$ & $331.4 \pm 24.4$ & $474.4 \pm 36.2$ & & & & & \\
\hline Purified & $141 \pm 7.8$ & $163.8 \pm 6.4$ & $414 \pm 4.0$ & - & - & - & - & - \\
\hline LosS & $65.8 \pm 0.5$ & $167.6 \pm 1.3$ & $60.4 \pm 0.2$ & & & & & \\
\hline$d f, F, P$ & $4,1694.2,0.0$ & $4,458.1,0.0$ & $4,397.9,0.0$ & $4,-, 0.0$ & $4,-, 0.0$ & $4,-, 0.0$ & $4,-, 0.0$ & $4,-, 0.0$ \\
\hline
\end{tabular}

Cont-H: Untreated crude haemolymph.

Inf-H: Treated haemolymph.

Expec.: Expected antibacterial peptide concentration.

Induced: IPTG induced E. coli culture.

Nonlnd: Non-induced $E$. coli culture.

Expressed P.: (Induced - Non-induced).

Purified: Purified expressed peptide using Ni-affinity column.

Loss: Loss due to purification.

sized defensin genes isolated from class Insecta. Thus, the orf of SpliDef (300 bp) was comparable in size to that of other Spodoptera sp. defensin-like genes (303-306 bp).

Reconstruction of the phylogenetic trees of the SpliDef nucleotide seuquence and its deduced polypeptide resulted in two different topologies. In spite of constructing two different tree topologies, both trees clustered the SpliDef sequence with that of $S$. frugiperda to indicate that they descend from a common ancestor. The grouping of some lepidopteran and dipteran defensins (e.g. M. brassicae with $A$. aegypti and S. littoralis with $D$. melanogaster) in one

Table 3 Antibacterial activity of the immunized haemolymph and the purified mature defensin peptide on gram (-) and gram (+) bacteria

Microorganism Antibacterial activity

(Gram stain)

\begin{tabular}{cc}
\hline $\begin{array}{c}\text { Immunized } \\
\text { haemolymph }\end{array}$ & $\begin{array}{c}\text { Mature purified } \\
\text { peptide }\end{array}$
\end{tabular}

24 h p.i. 48 h p.i. 24 h p.i. 48 h p.i.

\begin{tabular}{ccccc}
\hline Escherichia coli (-ve) & ++ & +++ & + & +++ \\
\hline Proteus vulgaris (-ve) & + & ++ & $(+)$ & ++ \\
\hline Klebsiella pneumoniae (-ve) & ++ & +++ & + & ++ \\
\hline Staphylococcus aureus (+ve) & +++ & +++ & ++ & +++ \\
\hline Streptococcus sanguinis (+ve) & +++ & +++ & +++ & +++ \\
\hline
\end{tabular}

$(+)$ : Inhibition zone less than $1 \mathrm{~mm}$ surrounding the $6 \mathrm{~mm}$ paper disk

+ : Inhibition less than positive control

++ : Inhibition comparable to positive control

+++ Inhibition more than $10 \mathrm{mg}$ penicillin; inhibition zones of references = $13 \pm 1 \mathrm{~mm}$ diam. sister clade indicated that they may be homologous or share some similarity. In addition, the lepidopteran defensin-like sequences were diverged in many sister clades as nucleotides but they were clustered in a monophyletic group as amino acids due to the difference in codon usage in the different insect species.

Although three signal peptide cleavage sites were detected, the most probable site is between positions 2324 . The detected glycosylation and glycation residues may serve for correct folding and stability of the protein. It was shown that the unglycosylated protein degrades quickly. Glycosylation may also play a role in cell-cell adhesion (a mechanism employed by cells of the immune system), as well [25]. In addition, 15 phosphorylation sites were identified. Reversible phosphorylation of proteins (using kinases and phosphatases) is considered an important regulatory mechanism that occurs in both prokaryotic and eukaryotic organisms [26]. It is very important in proteinprotein interaction via recognition domains $[27,28]$, (i.e. many proteins and receptors are switched "on" or "off" by phosphorylation and dephosphorylation). It may also result in a conformational changes in the structure of many peptides, causing them to become activated, deactivated or degraded [29].

Spacing pattern of our anionic defensin revealed a possible frameshift mutation of at least six residues within the conserved cysteine motif of SpliDef $\left(\mathrm{His}^{77}\right.$, $\mathrm{Leu}^{79}$, $\mathrm{Lys}^{81}, \mathrm{Gly}^{82}, \mathrm{Tyr}^{83}$ and $\mathrm{Gly}^{86}$ ) in comparison to (His ${ }^{73}$, $\mathrm{Leu}^{75}$, $\mathrm{Lys}^{77}, \mathrm{Gly}^{78}, \mathrm{Tyr}^{79}, \mathrm{Gly}^{82}$ ) of BmdefA [14]. Numbers refer to the prepropeptide sequence of a defensin. The first two anionic defensins of Amblyomma hebraeum 


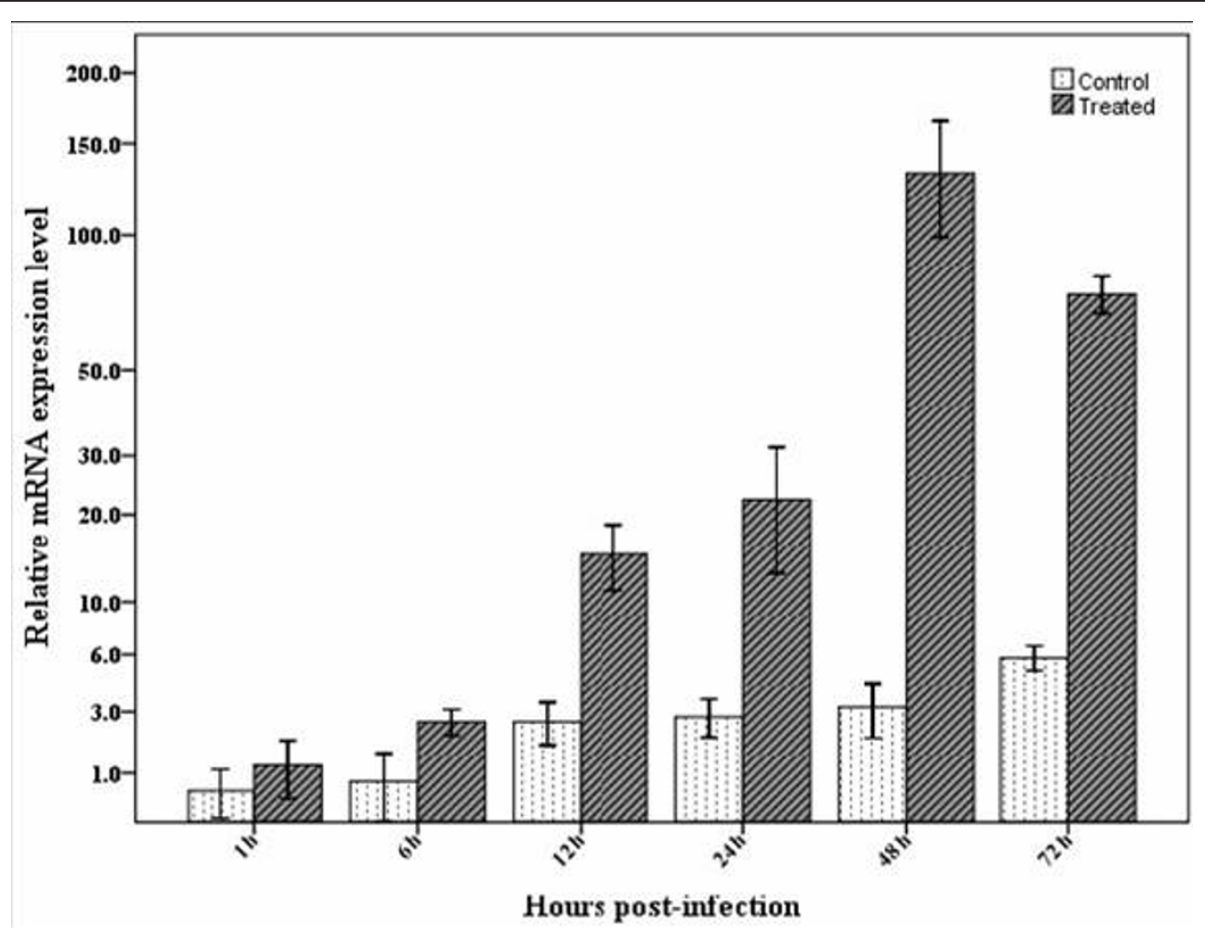

Figure 7 RT-qPCR of the SpliDef from RNA isolated from the haemolymph of control and bacteria-challenged S. littoralis larvae at 1, 6, 12, 24, 48 and $72 \mathrm{~h}$ p.i. Data were statistically analyzed and compared with control using ANOVA. Values The bars show the mean \pm SE of relative mRNA expression levels.

were reported by Lai et al. [30]. Similar properties were reported by Wen et al. [14] for a novel anionic defensin peptide (PI: 4.12) isolated from $B$. mori. These results were contrary to almost all known defensins, which were described as cysteine-rich cationic AMPs [e.g. [11,21].

Although most insect defensins are active against gram $(+)$ bacteria, the purified mature SpliDef exhibited activity against both gram (+) and gram (-) bacteria. According to Shai-Matsuzaki-Huang (SMH) model, antibacterial activity was ascribed to the interaction between the positively charged AMPs and the negatively charged microbial membrane components, which include LPSs in gram $(-)$ bacteria and polysaccharides in gram (+) bacteria [31]. However, this model has difficulty explaining the behaviours of anionic defensins like SpliDef. For example, the Amblyomma defensin-2 contains a net negative charge with a PI value of 4.44, and exerts antimicrobial activity against the gram (-) bacterium E. coli and the gram (+) bacterium S. aureus [30]. This suggests that anionic defensins might possess some novel antimicrobial mechanisms; although no convincing evidence is available until date. As the knowledge of anionic defensins is still poorly known, it is of interest to investigate the properties of the SpliDef.

Sequence motifs similar to the binding sites of TATA, CATT, IL-6-RE, and GATA transcription factors in mammals were found in promoter region of our sequence and almost in all genes that are up-regulated after immune challenge [32]. TATA, CATT, IL-6-RE, and GATA boxes were found adjacent to each other indicating that they work cooperatively in the transcriptional activation of the SpliDef gene as previously described in cecropin $\mathrm{A}_{1}$ gene in Drosophila [33]. Our results also showed that the relative transcription levels of SpliDef were up-regulated after bacterial-challenge, indicating the involvement of the SpliDef gene in immune responses of the Egyptian cotton leafworm, S. littoralis. The expression of SpliDef in haemocytes peaks at $48 \mathrm{~h}$ p.i. and gradually declines with time. These results were supported by the quantitative protein analysis which revealed the significant peak of increase at $48 \mathrm{~h}$ post-infcetion. Kaneko et al. [34] reported that the expression of BmDefensinB in fat body tissue of $B$. mori peaks at $8 \mathrm{~h}$ p.i. and declines with time. Ceraul et al. [35] demonstrated that the expression of two defensin isoforms in midgut and fat body tissues of the hard tick Dermacentor variabilis peak at $48 \mathrm{~h}$ p.i. with Rickettsia and gradually decline with time. The expression peak in fat body tissue may be retarded to be at $72 \mathrm{~h}$ p.i. in the case of defensin-2. Lopez et al. [21] found that the defensin expression pattern in fat body of bacteria-injected Rhodnius prolixus tissue is higher than in the intestinal tissue. This pattern may be 
due to the fact that the expression of defensin gene in deferent body tissues depends on the consequences of infection course of a pathogen (injected pathogen attacks haemocytes and fat body firstly and fed pathogen attacks alimentary canal firstly).

\section{Conclusions}

Our current results provide a typical anionic insect defensin gene (SpliDef) with a possible frameshift mutation. SpliDef plays an important immune role in S. littoralis by cooperating with other AMPs to control bacterial infection and it dominates at $48 \mathrm{~h}$ p.i. These findings would be helpful in defensin studies concerning ELISA, PCR and other related molecular and immunological techniques.

\section{Methods}

Insects and bacterial strains

A laboratory colony of the cotton leafworm, S. littoralis, used for our experiments was originally collected from okra field at Giza, Egypt in 1995 and maintained in the insectary of the Department of Entomology, Faculty of Science, Cairo University according to the technique described by El-Defrawi et al.[36]. Larvae were reared on a semisynthetic diet described by Levinson and Navon [37] and kept at $25 \pm 1{ }^{\circ} \mathrm{C}, 65-70 \% \mathrm{RH}$ and $14 \mathrm{~L}: 10 \mathrm{D}$ photoperiod cycle.

Two gram (+) bacteria, Staphylococcus aureus and Streptococcus sanguinis, and one gram (-) bacterial strain, Escherichia coli $\left(\mathrm{D}_{31}\right)$, were obtained from the Unit for Genetic Engineering and Agricultural Biotechnology, Faculty of Agriculture, Ain Shams University and used for insect immunization. Bacteria were grown in a peptone medium (1\%), supplemented with $1 \%$ meat extract and $0.5 \% \mathrm{NaCl}$, at $37^{\circ} \mathrm{C}$ in a rotary shaker.

\section{Bacterial challenge and haemolymph collection}

Bacterial challenge was performed by injecting 20 newly moulted fourth instar larvae with 2-5 $\mu$ l of approximately $1 \times 10^{6}$ (cells $\left./ \mathrm{ml}\right) \log$ phase bacteria dissolved in membrane-filtered saline using a thin-needled microsyringe. Haemolymph was collected 1, 6, 12, 24, 48 and 72 h p.i. at $4^{\circ} \mathrm{C}(500 \mu \mathrm{l} / \mathrm{each})$, containing few crystals of phenylthiourea to prevent melanization. Haemolymph was pooled by piercing a proleg with a fine, sterile needle. Haemolymph was aliquoted (100 $\mu \mathrm{l}$ each) and stored at $-80^{\circ} \mathrm{C}$ for a weak to be investigated. The same procedures were applied to control group except it was injected with saline without bacteria.

\section{DD-PCR using primers corresponding to well known defense genes}

Total RNA of the insect haemolymph (300-500 $\mu \mathrm{l})$ was extracted using RNeasy kit according to the manufacturer's instructions (Qiagen, Germany). Residual genomic DNA was removed from RNA using RNase-free DNase (Ambion, Germany). RNA was dissolved in DEPC-treated water, quantified using a BioPhotometer 6131 (Eppendorf) and analyzed on $1.2 \%$ denatured agarose gel to ensure its integrity. The $260 / 280$ and 260/230 ratios were examined for protein and solvent contamination.

A total of 100 ng of DNA-free total RNA was converted into cDNA using a mix of random and oligodT20 primers according to the ABgene protocol (ABgene, Germany). Synthesis of the first cDNA strand was performed in a thermal cycler (Eppendorf, Mastercycler 384, Germany) programmed at $42^{\circ} \mathrm{C}$ for $1 \mathrm{~h}, 72^{\circ} \mathrm{C}$ for $10 \mathrm{~min}$ and a soak at $4^{\circ} \mathrm{C}$. The cDNA was aliquoted and stored at -80 until processed (within a weak).

A total reaction volume of $25 \mu \mathrm{l}$ containing $2.5 \mu \mathrm{l} \mathrm{PCR}$ buffer, $1.5 \mathrm{mM} \mathrm{MgCl}_{2}, 200 \mu \mathrm{M}$ dNTPs, 1 U Taq DNA polymerase (AmpliTaq, Perkin-Elmer), $2.5 \mu \mathrm{l}$ of $10 \mathrm{pmol}$ primer (Table 1) and $2.5 \mu \mathrm{l}$ of each cDNA was cycled in a DNA thermal cycler (Eppendorf, Mastercycler 384, Germany). The amplification program was one cycle at $94^{\circ} \mathrm{C}$ for $5 \mathrm{~min}$ (hot start), followed by 40 cycles at $94^{\circ} \mathrm{C}$ for $1 \mathrm{~min}, 40^{\circ} \mathrm{C}$ for $1 \mathrm{~min}$ and $72^{\circ} \mathrm{C}$ for $1 \mathrm{~min}$. The reaction was then incubated at $72^{\circ} \mathrm{C}$ for $10 \mathrm{~min}$ for final extension. PCR product was visualized on $1.5 \%$ agarose gel and photographed using gel documentation system. For DNA contamination assessment, a no-reverse transcription control reaction was performed.

Eight reproducible bacterial-induced bands were eluted, cloned in PCR-TOPO vector (Invitrogen, USA) and sequenced using $M_{13}$ universal primer. Sequencing was performed using $\mathrm{T}^{7}$ Sequencing ${ }^{\mathrm{TM}}$ kit (Pharmacia, Biotech, USA) and model 310 automated sequencer (Applied Biosystems, Foster City, CA, USA). Analyses of nucleotide and deduced amino acid sequences were carried out using EditSeq-DNAstar Inc., Expert Sequence Analysis software, Windows 32 Edit Seq 4.00 (1989-1999) and ExPasy database http://expasy.org/tools/dna.html. Blast search for alignment of the obtained sequence with the published ones was done using database of NCBI http://blast.ncbi. nlm.nih.gov/Blast.cgi.

\section{Full length cDNA cloning and sequence analysis}

Based on the sequence and alignment data, specific primers for defensin-related sequences were designed and tried for reverse transcription polymerase chain reaction (RT-PCR). Primers were designed by the rules of highest maximum efficiency and sensitivity. Rules were followed to avoid formation of self and hetero-dimers, hairpins and self-complementarity. RT-PCR reaction was performed as previously described in this section regarding to the optimum annealing temperature $\left(T_{a}\right)$ for each specific primer set. Positive PCR products were visualized and eluted from the gel using GenClean Kit (Invitrogen Corporation, 
San Diego, CA, USA) following the manufacturer's instructions. The purified PCR products were cloned into $P C R-T O P O$ vector with TOPO TA cloning kit (Invitrogen, USA) following the manufacturer's instructions. Ligation mix was used to transform competent $E$. coli strain $\mathrm{TOPO}_{10}$ provided with the cloning kit. White colonies were screened using PCR as described earlier in this section. Five positive clones of SpliDef fragment were selected and sequenced (to exclude PCR errors certainly) using the specific forward and reverse primers. To study the characteristics of the promoter region of the SpliDef gene, promoter region was amplified from chromosomal DNA (extracted using DNeasy kit following the manufacturer's instructions) using PromF and PromR primers (Table 1). Sequencing and sequence analyses were performed as described early in this section. The core promoter region and the transcription start site of the SpliDef gene was predicted using Neural Network Promoter Prediction http://www.fruitfly.org/seq_tools/promoter.html and the minimum promoter score was set at 0.8 . In addition to the above mentioned analyses, ExPasy Proteomics Server http://expasy.org/tools was used to calculate physico-chemical parameters of the translated peptide (ProtParam tool). Furthermore, primary and secondary structure analyses, post-translational modifications and topology predictions were investigated using SignalP, NetCGlyc, NetOGlyc, NetGlycate, YinOYang, NetPhos, NetPhosK, Sulfinator, ProP, NetNES, TatP and TMHMM tools. Phylogenetic analyses of the nucleotide sequence and its deduced amino acids were done using Phylogeny.fr web service, One Click mode. Poorly aligned positions and divergent sequences were eliminated manually. Multiple alignment of 58 published defensin-related nucleotide sequences was done before phylogenetic analyses to approximate sequence lengths manually. $100 \%$ homologous sequences of the same species with different accession numbers were represented by only one sequence. The cloned DNA fragment was deposited in GenBank under the HQ603825 accession number.

\section{Expression of the mature defensin peptide}

$p$ PROEXTM HTa Prokaryotic Expression System kit (Life technologies, USA) was used to clone the purified PCR product corresponding to mature defensin peptide following the manufacturers' instructions. Charged $p$ PROEX $H T a$ vector was transformed into the competent $E$. coli strain $\mathrm{DH}_{5} \alpha$ provided with the kit. Gene expression was induced by IPTG as described by Goh et al. [38]. Induced and non-induced samples were analyzed on $12 \%$ Tricine SDS-PAGE and the expressed protein was affinity-purified on nickel-nitrilotriacetic acid Superflow resin (Qiagen, Germany) according to the manufacturer's protocol and quantified spectrophotometrically using Bio-Rad protein assay kit (Bio-Rad, USA) following the manufacturer's protocol. Standard curve was constructed by using Bovine gamma globulin (BGG).

\section{Antibacterial assay}

In vitro antimicrobial studies of the haemolymph samples as well as the purified mature peptide were carried out by the agar disk diffusion method with minor modifications $[39,40]$. Five milliliters of $0.6 \%$ melted LB agar $\left(52^{\circ} \mathrm{C}\right)$ were mixed with $100 \mu \mathrm{l}$ of viable bacterial suspension $\left(1.6 \times 10^{9}\right.$ cells $/ \mathrm{ml}$ ), and poured into a $9 \mathrm{~cm}$ plastic dish. Five microliters of each haemolymph and protein samples were applied to a $6 \mathrm{~mm}$ diameter paper disk and incubated at $37^{\circ} \mathrm{C}$. Total protein concentration was quantified spectrophotometrically in both the control and the bacterial-challenged samples using Bio-Rad protein assay kit (Bio-Rad, USA) following the manufacturer's protocol. The difference between the control and the treated samples was considered accumulated AMP in the haemolymph (subtraction method). Standard curve was constructed by using BGG. Haemolymph volumes were corrected for total protein concentration all over the experiment. Penicillin (10 mg/disc; obtained from Sigma) and normal saline solution were used as positive and negative controls, respectively. E. coli, Proteus vulgaris, Klebsiella pneumoniae, S. aureus and S. sanguinis were used for testing the antimicrobial activity. Inhibition zone diameters of five replicates were measured after 24-48 h. The degree of growth inhibition was quantitatively evaluated after $16 \mathrm{~h}$ by comparison with the growth inhibition resulting from the positive control.

\section{Quantitative real-time PCR (RT-qPCR)}

In order to estimate the comparative transcription rate of defensin, RT-qPCR was used. RT reaction was done as described above. Initially, $1 \mu \mathrm{l}$ of the $\mathrm{RT}$ reaction was diluted and used in a RT-qPCR reaction using defensin primers and untreated control to adjust the sample volume (ensure similar amplification profiles). $18 S$ rRNA gene was used as reference gene for RNA normalization. Each sample was measured thrice in a 96-well plate (Bio$\mathrm{rad})$ in a $30 \mu \mathrm{l}$ reaction volume. Samples were run on a BioRad $i$ Cycler machine under the following conditions: $95^{\circ} \mathrm{C}$ (5 min) for one cycle, and 40 cycles of $95^{\circ} \mathrm{C}$ (30 sec), $58^{\circ} \mathrm{C}(30 \mathrm{sec})$ and $72^{\circ} \mathrm{C}(60 \mathrm{sec})$. The PCR reagents were similar to the regular PCR with the addition of $1 \mu \mathrm{l}$ of a $1 /$ 1000 dilution of Sybr-Green I (Sigma, USA) and $2.5 \mu \mathrm{l}$ of a $1 / 1000$ dilution of fluorescein to control the background fluorescence. Subsequently, the adjusted sample volumes of cDNAs were used to amplify defensin gene in the haemolymph of control and treated insects at 1, 6, 12, 24, 48 and $72 \mathrm{~h}$ p.i. Fluorescent detection was performed at the annealing phase and during subsequent dissociation curve analysis to confirm that a single product had been amplified. The quantification cycles $(\mathrm{Cq})$ were calculated using 
the iQ5 Optical system software version 2.0. Primer dimers yielded a single sharp peak at the amplicon's melting temperature. No-template and no-reverse transcription reactions were used as negative control. Target amplification efficiency of the reaction was determined from the slope of a plot of Cq versus - $\log 10$ concentration of the initial number of target molecules and all assays showed high efficiency of amplification (90-96\%) and low intraand inter- assay variations. All RT-qPCR experiments adhered to the MIQE (Minimum Information for Publication of Quantitative Real-Time PCR Experiments) guidelines [41]. MIQE checklist is attached as additional file 1.

\section{Statistical analyses}

The gene expression levels were quantified relative to the expression of the $18 \mathrm{~S}$ rRNA gene using the Gene Expression Macro software (Bio-Rad, Hercules, Calif., USA), employing an optimized comparative $\mathrm{Cq}(\Delta \Delta \mathrm{Cq})$ value method. One way analysis of variance (ANOVA) and multiple comparison tests (Scheffé) were applied to protein concentration, inhibition zone and RT-qPCR results using SPSS (ver17.0) computer software (SPSS for Windows, SPSS Inc.). The scale type of Y-axis was adjusted to the power exponent of 0.25 at a safe mode to improve the quality of chart and to keep the relative difference between the control and the treated samples.

\section{Conflict of interests}

The authors declare that they have no competing interests.

\section{Additional material}

Additional file 1: MIQE checklist for authors, reviewers and editors All essential information (E) must be submitted with the manuscript. Desirable information (D) should be submitted if available. If using primers obtained from RTPrimerDB, information on GPCR target, oligonucleotides, protocols and validation is available from that source.

\footnotetext{
Acknowledgements

Thanks go to the Cairo University for supporting us to complete this work by the Cairo University grant no. CU-008-08. We also want to thank Prof Thomas A. Miller for his endless support and valuable comments that help us to improve the style of this paper.
}

\section{Author details}

'Department of Entomology, Faculty of Science, Cairo university, 9 Gamaa St. Giza, 12613, Egypt. ${ }^{2}$ Department of Molecular plant pathology, ALCADRl, City for Scientific Research and Technology Application, New Borg ElArab, Alex, 21934, Egypt.

\section{Authors' contributions}

AMS: Designed the overall study, carried out the molecular genetic studies optimization, performed data analysis, interpretation and manipulation, drafted and revised the manuscript, conceived of the study and participated in its coordination. EEH: Participated in the optimization of molecular genetic studies, performed data analysis and interpretation, conceived of the study and participated in its coordination. FHG: Participated in the optimization of molecular genetic studies, performed data analysis and interpretation, conceived of the study and participated in its coordination. All authors have read and approved the final manuscript.

Received: 15 June 2011 Accepted: 9 November 2011 Published: 9 November 2011

\section{References}

1. Breithaupt H: The new antibiotics. Nat Biotechnol 1999, 17:1165-1169.

2. Andreu D, Rivas L: Animal antimicrobial peptides: an overview. Biopolymers 1998, 47:415-433.

3. Hoffmann JA, Kafatos FC, Janeway CA, Ezekowitz RA: Phylogenetic perspectives in innate immunity. Science 1999, 284:1313-1318.

4. Barillas-Mury C, Wizel B, Han YS: Mosquito immune responses and malaria transmission: lessons from insect model systems and implications for vertebrate innate immunity and vaccine development. Insect Biochem Mol Biol 2000, 30:429-442.

5. Hoffmann JA, Hetru C: Insect defensins: inducible antibacterial peptides. Immunol Today 1992, 13:411-415.

6. Hetru C, Hoffman JA, Bulet P: Antimicrobial peptides from insects.Edited by: Brey PT, Hultmark D. Molecular Mechanisms of Immune Response in Insects. Chapman 1998:40-66.

7. Bulet P, Hetru C, Dimarcq JL, Hoffmann D: Antimicrobial peptides in insects; structure and function. Dev Comp Immunol 1999, 23:329-344.

8. Lamberty M, Ades S, Uttenweiler-Joseph S, Brookhart G, Bushey D, Hoffmann JA, Bulet P: Isolation from the lepidopteran, Heliothis virescens, of a novel insect defensin with potent antifungal activity. J Biol Chem 1999, 274:9320-9326.

9. Mandrioli M, Bugli S, Saltini S, Genedani S, Ottaviani E: Molecular characterization of a defensin in the IZD-MB-0503 cell line derived from immunocytes of the insect Mamestra brassicae (Lepidoptera). Biol Cell 2003, 95:53-57.

10. Volkoff AN, Rocher J, d'Alencon E, Bouton M, Landais I, Quesada-Moraga E, Vey A, Fournier P, Mita K, Devauchelle G: Characterization and transcriptional profiles of three Spodoptera frugiperda genes encoding cysteine-rich peptides. A new class of defensin-like genes from lepidopteran insects? Gene 2003, 319:43-53.

11. Landon L, Barbault F, Legrain M, Menin L, Guenneugues M, Schott V, Vovelle F, Dimarcq JL: Lead optimization of antifungal peptides with $3 \mathrm{D}$ NMR structures analysis. Protein Science 2004, 13:703-713.

12. Lee YS, Yun EK, Jang WS, Kim I, Lee JH, Park SY, Ryu KS, Seo SJ, Kim CH, Lee $\mathrm{IH}$ : Purification, cDNA cloning and expression of an insect defensin from the great wax moth, Galleria mellonella. Insect Mol Biol 2004, 13:65-72.

13. Freitak D, Wheat $C W$, Heckel DG, Vogel H: Immune system responses and fitness costs associated with consumption of bacteria in larvae of Trichoplusia ni. BMC Biol 2007, 5:56.

14. Wen H, Lan X, Cheng T, He N, Shiomi K, Kajiura Z, Zhou Z, Xia Q, Xiang Z, Nakagaki M: Sequence structure and expression pattern of a novel anionic defensin-like gene from silkworm (Bombyx mori). Mol Biol Rep 2009, 36:711-716.

15. Soo C, Sayah DN, Zhang X, Beanes SR, Nishimura I, Dang C, Freymiller E, Ting K: The identification of novel wound-healing genes through differential display. Plast Reconstr Surg 2002, 110:787-796.

16. Liang $P$, Averboukh L, Pardee AB: Distribution and cloning of eukaryotic mRNAs by means of differential display: refinements and optimization. Nucleic Acids Res 1993, 21:3269-3269.

17. Dimopoulos G, Richman A, Torre AD, Kafatos FC, Louis C: Identification and characterization of differentially expressed cDNAs of the vector mosquito, Anopheles gambiae. Proc Nat Acad Sci 1996, 93:13066-13074.

18. Ramalho-Ortigão JM, Temporal P, de Oliveira SM, Barbosa AF, Vilela ML, Rangel EF, Brazil RP, Traub-Cseko YM: Characterization of constitutive and putative differentially expressed mRNAs by means of expressed sequence tags, differential display reverse transcriptase-PCR and randomly amplified polymorphic DNA-PCR from the sand fly vector Lutzomyia longipalpis. Mem Inst Oswaldo Cruz 2001, 96:100-105.

19. Mong JA, Krebs C, Pfaff DW: Perspective: Micoarrays and differential display PCR: Tools for studying transcript levels of genes in neuroendocrine systems. Endocrinol 2002, 143:2002-2023.

20. Santana FA, Nunes FM, Vieira CU, Machado MA, Kerr WE, Silva WA Jr, Bonetti AM: Differentially displayed expressed sequence tags in Melipona 
scutellaris (Hymenoptera, Apidae, Meliponini) development. Anais da Academia Brasileira de Ciências 2006, 78:69-73.

21. Lopez L, Morales G, Ursic R, Wolff M, Lowenberger C: Isolation and characterization of a novel insect defensin from Rhodnius prolixus, a vector of Chagas disease. Insect Biochem Molec Biol 2003, 33:439-447.

22. Ueda K, Imamura M, Saitol A, Sato R: Purification and CDNA cloning of an insect defensin from larvae of thelongicorn beetle, Acalolepta luxuriosa. Appl Entomol Zool 2005, 40:335-345.

23. Hwang J-S, Lee J, Kim Y-J, Bang H-S, Yun E-Y, Kim S-R, Suh H-J, Kang B-R, Nam S-H, Jeon J-P, Kim I, Lee DG: Isolation and Characterization of a Defensin-Like Peptide (Coprisin) from the Dung Beetle, Copris tripartitus. Internat J Peptides 2009, 136284:5.

24. Wang Q, Liu Y, He H-J, Zhao X-F, Wang J-X: Immune responses of Helicoverpa armigera to different kinds of pathogens. BMC Immunol 2010, 11:9-12.

25. Varki A, Cummings RD, Esko JD, Freeze H, Stanley P, Bertozzi CR, Hart GW, Etzler ME: Essentials of Glycobiology. Cold Spring Harbor Laboratories Press (NY), La Jolla, California, USA; 22009.

26. Barford D, Das AK, Egloff MP: The structure and mechanism of protein phosphatases: insights into catalysis and regulation. Annu Rev Biophys Biomol Struct 1998, 27:133-164.

27. Babior BM: NADPH oxidase: an update. Blood 1999, 93:1464-1476.

28. Cole PA, Shen K, Qiao Y, Wang D: Protein tyrosine kinases Src and Csk: a tail's tale. Curr Opin Chem Biol 2003, 7:580-585.

29. Olsen JV, Blagoev B, Gnad F, Macek B, Kumar C, Mortensen P, Mann M: Global, in vivo, and site-specific phosphorylation dynamics in signaling networks. Cell 2006, 127:635-648.

30. Lai R, Lomas LO, Jonczy J: Two novel non-cationic defensin-like antimicrobial peptides from haemolymph of the female tick, Amblyomma hebraeum. Biochem J 2004, 379:681-685.

31. Zasloff M: Magainins, a class of antimicrobial peptides from Xenopus skin: Isolation characterization of two active forms, and partial cDNA sequence of a precursor. PNAS 1987, 84:5449-5453.

32. Cheng T, Zhao P, Liu C, Xu P, Gao Z, Xia Q, Xiang Z: Structures, regulatory regions, and inductive expression patterns of antimicrobial peptide genes in the silkworm Bombyx mori. Genomics 2006, 87:356-365.

33. Kadalayil L, Petersen UM, Engstrom Y: Adjacent GATA and kappa B-like motifs regulate the expression of a Drosophila immune gene. Nucleic Acids Res 1997, 25:1233-1239.

34. Kaneko Y, Tanaka H, Ishbashi J, Iwasaki T, Yamakawa M: Gene expression of a novel defensin antimicrobial peptide in the silkworm, Bombyx mori. Biosci Biotechnol Biochem 2008, 72:2353-2361.

35. Ceraul S, Dreher-Lesnick S, Gillespie J, Rahman M, Azad A: New tick defensin isoform and antimicrobial gene expression in response to Rickettsia montanensis challenge. Infec Immun 2007, 75:1973-1983.

36. El-Defrawi ME, Tappozada A, Mansour N, Zeid M: Toxicological studies on Egyptian cotton leaf worm Prodenia litura (F.)1: susceptibility of different larval instars of Prodenia litura to insecticides. J Econ Entomol 1964, 57:591-593.

37. Levinson ZH, Navon A: Ascorbic acid and unsaturated fatty acids in the nutrition of the Egyptian cotton leaf worm. J Insect Physiol 1969, 15:591-595.

38. Goh EB, Bledsoe PJ, Chen LL, Gyaneshwar P, Stewart V, Igo MM: Hierarchical control of anaerobic gene expression in Escherichia coli K12: the nitrate-responsive NarX-NarL regulatory system represses synthesis of the fumarate-responsive DcuS-DcuR regulatory system. $J$ Bacteriol 2005, 187:4890-4899.

39. NCCLS: Performance standards for antimicrobial disc suspectibility tests. Approved Standard NCCLS Publication M2-A5 Villanova, PA, USA; 1993.

40. Favel A, Steinmetz MD, Regli P, Olivier EV, Elias R, Balansard G: In vitro antifungal activity of triterpenoid saponins. Planta Med 1994, 60:50-53.

41. Bustin SA, Benes V, Garson JA, Hellemans J, Huggett J, Kubista M, Mueller R, Nolan T, Pfaffl MW, Shipley GL, Vandesompele J, Wittwer CT: The MIQE Guidelines: Minimum Information for Publication of Quantitative RealTime PCR Experiments. Clinical Chem 2009, 55:611-622.

doi:10.1186/1471-2199-12-47

Cite this article as: Seufi et al: Identification, phylogenetic analysis and expression profile of an anionic insect defensin gene, with antibacterial activity, from bacterial-challenged cotton leafworm, Spodoptera littoralis. BMC Molecular Biology 2011 12:47.

\section{Submit your next manuscript to BioMed Central and take full advantage of:}

- Convenient online submission

- Thorough peer review

- No space constraints or color figure charges

- Immediate publication on acceptance

- Inclusion in PubMed, CAS, Scopus and Google Scholar

- Research which is freely available for redistribution 